J. M. Van Camp · V. Tomaselli • R. Drongowski

A. G. Coran

\title{
Bacterial translocation in the newborn rabbit: effect of age on frequency of translocation
}

Accepted: 27 May 1994

\begin{abstract}
Sepsis is a significant cause of morbidity and mortality in neonates, and in a significant number of cases no predisposing factors can be identified. We hypothesize that bacterial translocation (BT) may be the etiology of neonatal sepsis when no source is identified. Mesenteric lymph nodes (MLN), spleen (SPL), and liver (LIV) were harvested from 36 rabbit pups ranging in age from 4 to 24 days and divided into three groups based on their age: group I, 4-6 days; group II, 13-15 days; and group III, 22-24 days. Tissues from each organ were homogenized and placed in both aerobic and anaerobic environments. After $48 \mathrm{~h}$ the number of colony-forming units/g tissue was identified. The total percentage of positive growth was significantly higher in group I for MLN $(33 \%)$ and LIV (23\%) when compared to groups II and III ( $<4 \%$ for both groups). Gram-negative growth (as selected by MacConkey [MC] media) was significantly higher in all tissue specimens from group I (MLN $=35 \%, \mathrm{SPL}=20 \%, \mathrm{LIV}=25 \%)$ compared to groups II and III ( $0 \%$ growth in all MC plates, $P<0.01$ ). These data support the hypothesis that spontaneous BT occurs with significant frequency in the neonate.
\end{abstract}

Key words Bacterial translocation $\cdot$ Neonate

\author{
J. M. Van Camp \\ University of Michigan Medical Center, Ann Arbor, MI, USA \\ V. Tomaselli \\ Section of Pediatric Surgery, C. S. Mott Children's Hospital, \\ Ann Arbor, MI, USA
}

R. Drongowski

Pediatric Surgery Research Laboratories, C. S. Mott Children's Hospital, Ann Arbor, MI, USA

\section{A. G. Coran ( $)$}

Section of Pediatric Surgery, L2110 MCHC, University of Michigan Medical School, Box 0245 C. S. Mott Children's Hospital, Ann Arbor, MI 48109, USA

\section{Introduction}

Neonatal sepsis is a significant cause of morbidity and mortality in neonatal intensive care units. Many neonates dying of sepsis or multiple-system organ failure (MSOF) have no source of infection or predisposing factor identified. Bacterial translocation (BT), the process of intestinal bacteria invading extraintestinal tissue and causing infection and disease, was first proposed by Fine and coworkers in the 1960s [1]. Since then, clinical evidence has accumulated indicating that the gastrointestinal (GI) tract is frequently the reservoir for bacterial systemic infections, which may lead to MSOF and death.

The majority of clinical and animal studies to date have focused on several high-risk groups of adult patients and animals, including burn and trauma victims, as well as septic and immunocompromised patients and animals [2-7]. These studies suggest that the normal adult does not have BT because of the presence of: (1) an intact epithelial barrier; (2) normal host immune defenses; and (3) normal GI tract microflora [1]. However, several factors that promote BT in the stressed adult are present in the normal neonate [2], including changes in intestinal colonization, immature host immune defenses, and the increased permeability of the immature intestinal epithelial lining [8]. The following study was undertaken to specifically evaluate the frequency of BT in the normal newborn and to determine the effect of age on the frequency of BT.

\section{Materials and methods}

Experiments were performed by a single investigator using identical techniques over a period of 2 months. Rabbits were killed in a random fashion to account for possible bias due to a learning curve. Thirty-six New Zealand white rabbit pups ranging in age from 4 to 24 days were raised by their mother until 24 to $48 \mathrm{~h}$ before delivery to our laboratory. The rabbits were allowed to feed ad libitum from their mother until the time of separation and then were given one feeding every $24 \mathrm{~h}$ by the University Laboratory Animal Maintenance department. The rabbits were divided into three groups: group I consisted of animals 4-6 days 


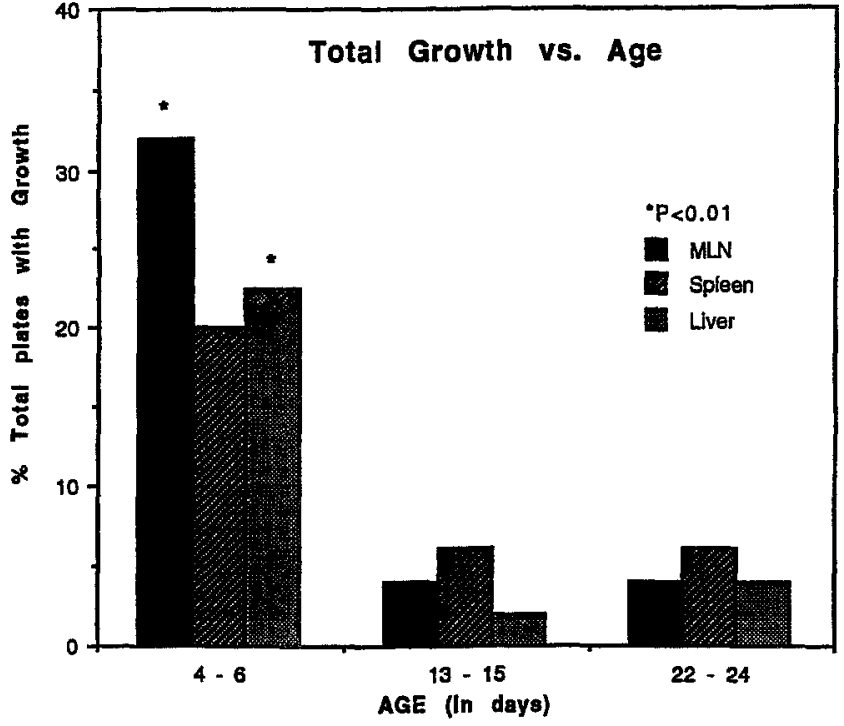

Fig. 1 Total bacterial growth in tissue specimens in relation to age ( $M L N$ mesenteric lymph nodes)

old, group II 13-15 days old, and group III 22-24 days old. The rabbits were sedated with acepromazine $1 \mathrm{mg} / \mathrm{kg} \mathrm{SC}$ and ketamine $50 \mathrm{mg} / \mathrm{kg}$ IM. Under sterile conditions, a midline incision was made from xyphoid to pubis without entering the peritoneum. Using sterile gloves and instruments, the peritoneum was opened and the mesenteric lymph-node (MLN) complex located at the base of the small-bowe mesentery was identified, isolated, excised, and placed in a sterile container. Using separate sets of sterile instruments, representative sections of spleen (SPL, 25-400 mg) and liver (LIV, 50-650 mg) were also removed.

The harvested tissues were each weighed and homogenized in $800 \mathrm{ml}$ brain-heart infusion broth; $50-\mu \mathrm{l}$ aliquots of homogenized tissue solution were plated on four separate plates that included MacConkey (MC) media in aerobic and anaerobic environments and colistin naladixic acid (CNA) media in aerobic and anaerobic environments. After $48 \mathrm{~h}$, the number of colony-forming units (CFU) per plate were identified. The number of $\mathrm{CFU} / \mathrm{g}$ tissue was calculated, and growth was considered positive if greater than $50 \mathrm{CFU} / \mathrm{g}$ were identified. Statistical analysis was performed on the Michigan Terminal System using MIDAS. Chi-square analysis with $P$ value less than 0.05 was considered significant.

Animal welfare policies and standards of the American Association for the Accreditation of Laboratory Animal Care were followed in conjunction with the animal experimentation.

\section{Results}

Group I had a significantly greater amount of total growth in the MLN and LIV specimens (33\% and 23\%, respectively) when compared to the total growth of the same tissues in groups II and III (less than $4 \%$ for each tissue and group). Although the total amount of growth from the SPL specimen was also greater in group I (18\%), there was no statistically significant difference between group I and group II $(6 \%)$ or III (6\%) (Fig. 1).

Gram-negative growth, as selected by MC plates, was significantly higher in group I for all three tissues. Percentages of positive growth on MC plates for group I rabbits were as follows: $\mathrm{MLN}=35 \%, \mathrm{SPL}=20 \%$, and $\mathrm{LIV}=25 \%$. No growth was seen on any MC plates in group II or III

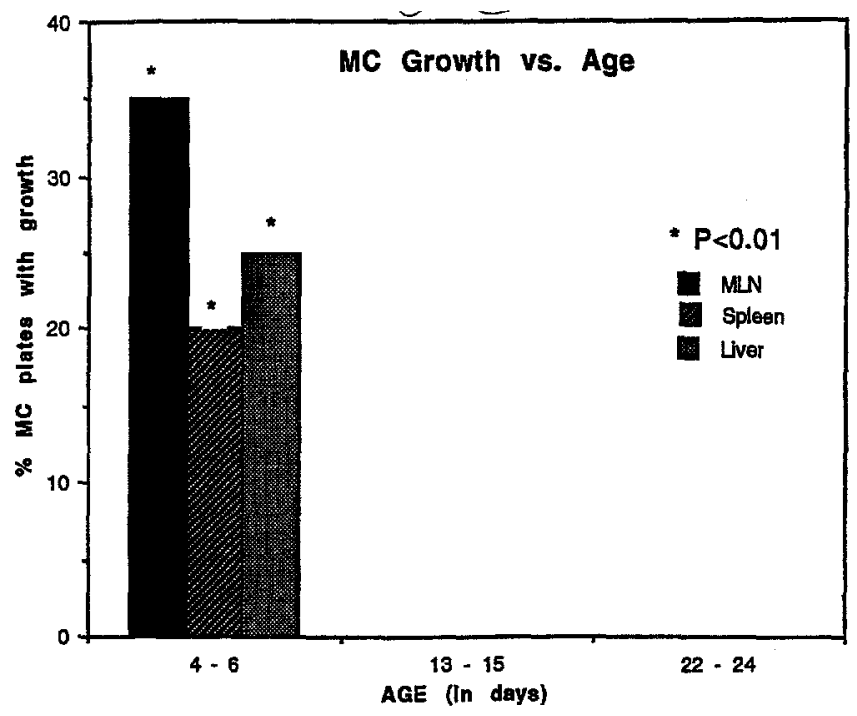

Fig. 2 Bacterial growth in MacConkey $(M C)$ media in relation to age ( $M L N$ mesenteric lymph nodes)

(Fig. 2). Gram-negative aerobic growth was statistically higher in group I for MLN (42\%) and LIV (25\%) when compared to groups II and III (0\% growth in both). The percentage of SPL gram-negative aerobic growth was higher in group I (17\%) but not statistically different from that in groups II and III (0\% in both). Although growth on anaerobic $\mathrm{MC}$, aerobic $\mathrm{CNA}$, and anaerobic CNA tended to be greater in group I, statistical significance was found only in LIV tissue of group I plated on CNA in an anaerobic environment ( $30 \%$ vs. $0 \%$ ).

\section{Discussion}

MSOF is associated with high mortality, ranging from $30 \%$ to $100 \%$ [9]. Many patients dying of MSOF have bacteremia for which no septic focus is identified [7]. Based on numerous clinical and experimental studies, it is now generally accepted that the intestine is frequently the reservoir for bacteria causing systemic sepsis in patients with clinically occult infections [1]. The process of intestinal bacteria invading extra-intestinal tissues has been termed BT.

BT has been studied and reproduced in many adult clinical and animal models [2-7]. Based on these models, Deitch has surmised that BT does not occur in healthy animals or humans because of the presence of: (1) an intact epithelial barrier; (2) normal host immune defenses; and (3) normal GI tract microflora that prevent bacterial overgrowth with potential pathogens (colonization resistance) [1]. Although current literature suggests that the above factors are altered in neonates, very few studies on sick neonates and no studies on normal neonates have been performed to evaluate the process of BT in the newborn. The present study suggests that BT does occur with significant frequency in the normal neonatal population. 


\section{The intestinal barrier}

It has been assumed that newborn infants, particularly those who are premature, are more prone to BT because of the immaturity of the intestinal epithelial barrier [10]. Lawrence et al. demonstrated that the neonatal intestine is able to absorb complete macromolecules during the first days to weeks of life in comparison with adult animals, who have a lower uptake of macromolecules [11]. Udall et al. also noted an increase in the uptake of intestinal antigens in newborn animals in comparison with adult animals [12]. These observations lend support to the hypothesis that BT occurs in premature infants with necrotizing enterocolitis (NEC) and often leads to sepsis and MSOF, which is further supported by the studies of Wilson and Kanto, who suggest that mucosal immaturity alone may be the most important factor in the etiology of NEC $[13,14]$. Inadequacy of the GI barrier in normal neonates may explain the increased rate of BT, which has been demonstrated in the present study. Further studies designed to specifically evaluate the intestinal epithelium of the normal neonate must be performed to confirm or refute this theory.

\section{Immune function}

There are conflicting reports regarding the role of the host immune system in the process of BT. Wells et al. performed studies on immunogenically altered strains of mice and concluded that translocation appeared to depend more on the species of intestinal microbe than on the immune status of the host [10]. On the other hand, Alverdy et al. demonstrated that BT occurred more often in animals given total parental nutrition and that this was associated with a decrease in mucosal and biliary IgA [15]. In further experiments, Alverdy and Aoys demonstrated that dexamethasone-treated animals developed $\mathrm{BT}$ to $\mathrm{MLN}$ in association with a marked decrease in $\operatorname{IgA}$ concentration in their bile [16].

Although an infant is born with most immune mechanisms fully developed, it is immunologically inexperienced and relatively susceptible to bacterial infection $[17,18]$. There is little immunoglobulin production at birth except for IgM [19]. Previous investigators have demonstrated that antibodies in the form of serum and secretory IgA are slow to appear in the infant [20]. Torleiv et al. recently reported that IgA immunocytes seem to appear in the human intestine 1 to 2 weeks after birth [21]. It is likely that secretory $\operatorname{IgA}$ acts at the epithelial surface of the intestine to protect the GI tract from the proliferation of bacterial micro-organisms [22]. The low level of secretory IgA antibodies found in neonates may be partially compensated for by the secretion of IgM molecules; however, the IgM molecule is less stable than the IgA molecule [20] and may not provide adequate mucosal protection against BT. In addition to low IgA levels, defects in opsonization and serum bactericidal capacity have been observed in young animals [18].

Finally, the role of breast milk and its provision of passive immunity to the neonate has yet to be elucidated in the prevention of BT. The present study involved rabbit pups who were allowed to feed ad libitum from their mothers until 24 to $48 \mathrm{~h}$ prior to the study and were then fed Formulac via a gastric feeding tube one or two times prior to harvesting of tissues. Rabbits in the oldest age group had been naturally weaned from their mother and were allowed to feed ad libitum Purina rabbit pellets prior to harvesting. A fully breast-fed human infant receives numerous nonspecific host defense factors, such as lactoferrin, lysozyme, and leukocytes, as well as $500 \mathrm{mg}$ secretory IgA per day via the milk [20]. Several investigators have demonstrated the ability of breast milk to protect against GI infections [19, 23, 24]; however, neonates fed only human milk still develop NEC [25].

\section{Bacterial colonization}

In virtually all the human and animal reports on BT, the most common organisms isolated are the Enterobacteriacea [15]. Enterobacteria are gram-negative aerobes that are found in the normally colonized GI tract. The present study supports the previous investigators' findings: a significantly higher number of CFU/g tissue found on the aerobic MC plates (selective for gram-negative bacteria). It is interesting to note that although anaerobic bacteria are more abundant and are most likely the first to colonize the GI tract, the aerobic bacteria are mainly involved in BT. Although not significant in the present study, the smallbowel swabs suggested that a majority of gram-positive growth occurred in the small bowel although the majority of gram-negative growth was found in the abdominal tissue specimens.

Mammals have a germ-free intestine at the time of birth. Previous investigators have demonstrated by means of fecal swabs that normal neonates are rapidly colonized within the first few days of life by a succession of organisms from their mothers and the environment $[24,26,27]$. Lawrence et al. demonstrated that a germ-free animal that has been exposed to a single strain of bacteria will experience an overgrowth of that organism with potential subsequent intestinal mucosal damage from that bacterium, even though it is not normally a pathogen. Animals who have been previously colonized with normal bacterial flora are not susceptible to intestinal mucosal damage when exposed to the same strain of bacteria. This observation suggests that exposure of the germ-free and, by inference, the newborn animal, to one or a small number of species of bacteria that can multiply without competition may lead to intestinal damage [11]. This difference in intestinal colonization and potential susceptibility to mucosal damage may explain the higher rate of BT in newborns, which was demonstrated in the present study.

\section{Relationship of BT to MSOF}

The presence of viable bacteria in the MLN has typically been accepted as an indicator of BT. Support for this concept has been provided by Tokyay et al., who induced 
BT by subjecting minipigs to burn injury. Their major finding was that removal of the MLN prevented postburn translocation of bacteria and systemic sepsis [6], which suggests that indigenous bacteria translocate mainly via the lymphatics and that the presence of viable bacteria in MLN is an appropriate indicator of BT.

Finally, the presence of viable bacteria in MLN does not necessarily lead to bacteremia and/or MSOF. This association will be better elucidated if future studies not only report whether MLN cultures are positive or negative, but also quantify the amount of growth that occurs in the nodes. There are no data in the literature that indicate how much growth in the MLN is required to consistently cause systemic infection and/or MSOF. Some authors feel that the important factor determining whether or not dissemination of the bacteria will occur is the bacterial characteristics in relation to host defenses [2]. The number of bacteria needed to cause systemic infection in the newborn may be significantly different than the number needed in the adult, possibly because of differences in host defenses. The present study considered any growth greater than $50 \mathrm{CFU} / \mathrm{g}$ as positive growth; however, this is an arbitrary number and further study of this parameter is needed.

In conclusion, we have demonstrated that a significant number $(23 \%-33 \%)$ of neonatal rabbits have indigenous bacteria in the LIV and MLN. Most of the growth demonstrated in these tissue is gram-negative and aerobic, which is consistent with BT from the intestine. These data support the hypothesis that spontaneous BT occurs with significant frequency in the neonate, while it is rare in older animals unless they are subjected to stress. The specific differences between neonates and adult animals that allow spontaneous BT in the neonates and not the adults are not known. Three possible explanations for the increase in BT in the neonate are: (1) increased permeability of the neonatal intestinal epithelial barrier; (2) relative immaturity of the neonatal immune system; and (3) differences in the bacterial colonization of the neonatal and adult GI tracts.

Further studies evaluating the above explanations in normal neonates as well as investigation into the clinical significance of the presence of spontaneous BT need to be carried out. Eventually, further understanding of $\mathrm{BT}$ in the normal neonate may lead to better treatment of diseases such as neonatal sepsis, NEC, and MSOF.

\section{References}

1. Deitch $E$ (1990) The role of intestinal barrier failure and bacterial translocation in the development of systemic infection and multiple organ failure. Arch Surg 125: 403-404

2. Jackson R, Smith S, Wadowsky R, DePudyt L, Rowe M (1991) The effect of $E$. coli virulence on bacterial translocation and systemic sepsis in the neonatal rabbit model. J Pediatr Surg 26: $483-486$

3. Jones W, Minei J, Barber A, et al (1990) Bacterial translocation and intestinal atrophy after thermal injury and burn wound sepsis. Ann Surg 211: 399-405
4. Lelli J, Drongowski R, Coran A, Abrams G (1992) Hypoxiainduced bacterial translocation in the puppy. J Pediatr Surg 27: 974-982

5. Salman F, Buyruk M, Gurler N, Celik A (1992) The effect of surgical trauma on the bacterial translocation from the gut. J Pediatr Surg 27: 802-804

6. Tokyay R, Zeigler S, Loick H, et al (1992) Mesenteric lymphadenectomy prevents postburn systemic spread of translocated bacteria. Arch Surg 127: 384-388

7. Zhi-Young S, Yuan-Lin D, Xiao-Hong W (1992) Bacterial translocation and multiple system organ failure in bowel ischemia and reperfusion. J Trauma 32: 148-153

8. Koloske A (1990) A unifying hypothesis for pathogenesis and prevention of necrotizing enterocolitis. J Pediatr 117: S69-S74

9. Sullivan B, Swallow C, Girotti M, Rotstein O (1991) Bacterial translocation induces procoagulant activity in tissue macrophages. Arch Surg 126: 586-590

10. Wells C, Jechorek R, Gillingham K (1991) Relative contributions of host and microbial factors in bacterial translocation. Arch Surg 126: $247-252$

11. Lawrence G, Bates J, Gaul A (1982) Pathogenesis of neonatal necrotizing enterocolitis. Lancet 16: 137-139

12. Udall J, Pang K, Fritze L, Kleinman R, Walker W (1981) Development of gastrointestinal mucosal barrier. I. The effect of age on intestinal permeability to macromolecules. Pediatr Res 15: $241-244$

13. Wilson R, Kanto W, McCarthy B, et al (1982) Short communication. Age at onset of necrotizing enterocolitis: an epidemiologic analysis. Pediatr Res 16: 82-84

14. Kanto W, Wilson R, Breart G, et al (1987) Perinatal events and necrotizing enterocolitis in premature infants. Am $\mathbf{J}$ Dis Child 141: $167-169$

15. Alverdy J, Aoys E, Moss G (1988) Total parenteral nutrition promotes bacterial translocation from the gut. Surgery 104: $185-190$

16. Alverdy J, Aoys E (1991) The effect of glucocorticoid administration on bacterial translocation. Ann Surg 214: 719-723

17. Tomaselli V, Van Camp J, Coran A (1995) Intestinal bacterial translocation in the newborn. J Parenter Enter Nutr (in press)

18. Lassiter H, Christensen R, Parker C, Rothstein G (1988) Neutrophil-mediated killing, opsonization, and serum-mediated killing of Escherichia coli $\mathrm{K} 1$ by neonatal rats. Biol Neonate 53: 156-162

19. Goldman A, Ham Pong A, Goldblum R (1985) Host defenses: development and maternal contributions. Adv Pediatr 32: 71-100

20. Hanson L, Ahistedt S, Andersson B, et al (1985) Protective factors in milk and the development of the immune system. Pediatrics 75 [Suppl]: $172-176$

21. Torleiv R, Thrane P, Stoltenberg L, Vege A, Brandtzaeg P (1992) Development of intestinal mucosal immunity in fetal life and the first postnatal months. Pediatr Res 32: 145-149

22. Walker W, Isselbacher K (1974) Uptake and transport of macromolecules by the intestine. Possible role in clinical disorders. Gastroenterology 67: 531-550

23. Sherman P, Forstner J, Forstner G (1989) Mucosal barrier and its defense during the perinatal period. Human Gastrointestinal Development, Raven Press, New York, pp 687-698

24. Mata L, Urrutia J (1971) Intestinal colonization of breast-fed children in a rural area of low socioeconomic level. Annals New York Academy of Sciences, INCAP Publication I 519: 93-109

25. Anderson D, Kliegman R (1991) The relationship of neonatal alimentation practices to the occurrence of endemic necrotizing enterocolitis. Am J Perinatol 8: 62-67

26. Williams Smith H, Crabb W (1961) The faecal bacterial flora of animals and man: its development in the young. J Pathol Bacterol 82: $53-66$

27. Bennet R, Eriksson M, Tafari N, Nord C (1991) Intestinal bacteria of newborn Ethiopian infants in relation to antibiotic treatment and colonization by potentially pathogenic gram-negative bacteria. Scand I Infect Dis 23: 63-69 